\title{
Concept Analysis of Futile Care in the Oncology Nursing: A Hybrid Model
}

\author{
Forough Rafii ${ }^{1}$, Hadi Ranjbar ${ }^{2}$, Mohammadreza Dinmohammadi ${ }^{3}$, Farshid Alazmani Noodeh ${ }^{1 *}$ \\ ${ }^{1}$ Department of Nursing, School of Nursing and Midwifery, Iran University of Medical Sciences, Tehran, Iran; ${ }^{2}$ Mental Health \\ Research Center, Psychosocial Health Research Institute, Iran University of Medical Science, Tehran, Iran; ${ }^{3}$ Department of \\ Nursing, School of Nursing and Midwifery, Zanjan University of Medical Sciences, Zanjan, Iran
}

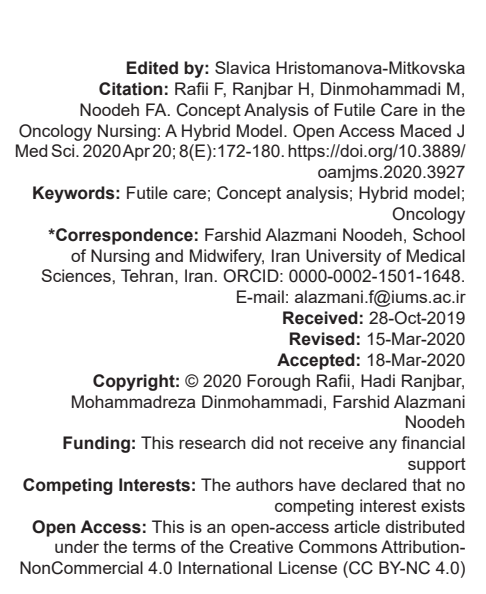

Introduction

Cancers are among conditions that have poor prognosis. Many patients with cancer die in the intensive care units (ICUs) which mean that they receive cares that do not increase their chance of survival and use crucial resources of systems [1]. Increased healthcare costs and lack of clear definition for this concept propose the necessity to consider futile care [2].

Care is a central concept in nursing that differentiates it from other health professions [3]. The services and cares that do not affect the quality of life of patients were considered as futile in the context of medicine and nursing [4]. Despite the advances in medical care and increase in survival of cancer patients, some cares do not benefit the patient outcome or quality of life. These cares increase the cost of health systems and use vital resources. Due to the shortness of resources rapid increase in its costs around the world, economic specialists and managers are challenged to find new methods to limit futile care [5].

In health-care centers, statements such as "what kind of care is this futile care" and "this patient did not need this diagnostic or therapeutic practice, why it was performed for him?" exist [6]. While the term of futile care was used extensively in the literature, we did not find no clear and comprehensive definition in the oncology setting that can indicate this issue of what caregivers mean by futile care [1], [2]. Professional groups have presented different meanings for futile care. The most critical problem of them is that they tried to use quantitative indexes for determination of futile care while there is no unified and clear definition for this concept, especially in oncology nursing [7], [8].

The definition of futile care is different based on the conditions of patients and the personal values of health-care team members [9]. Futile care is also dependent on the perspective toward life, moral beliefs, and judgment about successful and unsuccessful treatment. Despite different definitions, no common agreement exists for these definitions and they are dependent on the values and beliefs of patients, families, and health-care team members [10].

When the concept of futile care is addressing, the first question is "what is the purpose of futile or effective care in the context and culture of interest?" [9]. Different roles that health-care team members have 
in dealing with these patients lead to a gap in their understanding of nature, reasons, and dimensions [11]. Griener (1995) and Scanlon (2014) believe that despite different definitions for futile care, there are many ambiguities, and this has avoided the clarity of its clinical application and benefits [12], [13]. This ambiguity can lead to wrong applications in the nursing profession [14]. The existence of ambiguity and complexity in concept and also its multidimensionality shows the necessity to identify and explain this concept in nursing context [15]. In this study, it has been attempted to use the concept analysis to clarify the futile care concept in the context of oncology nursing of Iran.

\section{Materials and Methods}

Concept analysis is a valuable method to clarify those concepts that are highly applicable and have ambiguous meaning in nursing practice [16]. In the present study, the hybrid model which was developed by Schwartz-Barcott and Kim was used to explain the concept. The hybrid model has three-phase including theoretical phase, fieldwork phase, and final analytical phase. The process is demonstrated in Figure 1. The main objective of the theoretical phase is to create and complement a proper context to analyze and define the concept. At the end of this phase, the researcher presents an operational definition for the fieldwork phase. The objectives of this phase include strengthening and refining the concept formed in the

Theoretical Phase

Searching related literature. Results in table 1 and 2

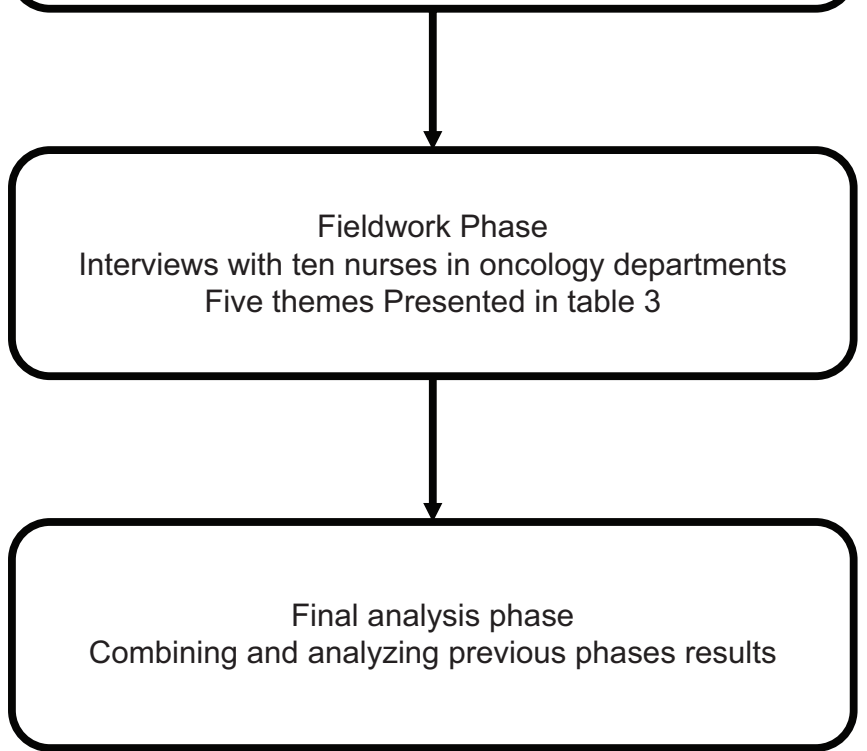

Figure 1: The flowchart of hybrid model concept analysis first phase and point to the experimental component. In this phase, qualitative data collection was used. The third phase included the integration of theoretical phase and fieldwork phase findings [15], [17].

In the first phase, through databases such as MEDLIN, Web of Science, Google Scholar, Proquest, Ovid, Iranmedex, and Maglran, 1829 articles about futile care were searched without time limitation. The search was performed considering keywords, including ineffectively care, futile care, futility, insufficient care, improper care, cancer, oncology, and malignancy. All articles from 1955 to 2017 were investigated, and finally, 124 English articles and 4 Persian articles were found. Then, studies were investigated in terms of inclusion criteria, including keywords, relatedness, access to the full text, and uniqueness, and finally, 33 articles were selected. At the fieldwork phase, the semistructured interviews were done with ten nurses. The first author directed all the interviews by asking openended questions and semi-structured interviews. The items used in semi-structured interviews were designed by reviewing the literature, and further questions were derived from the participants' responses. For instance, some of the questions were as follows:

\section{- What do you think about futile care? \\ - $\quad$ Can care be fundamentally futile? \\ - Why you take care of a patient who is going to die? \\ Have you ever had experience in futile care? Explain.}

The inclusion criteria were having at least a bachelor's degree in nursing, having at least 5 years of experience in critical care or cancer units, and being willing to take part in the study. Data collection tool included semi-structured interview with open-ended questions with 10 nurses with the characteristics including seven female nurses and three male nurses where six nurses were working in oncology, two nurses were working in ICU, and two nurses were working in palliative care center, and seven of them had bachelor's degree, and three of them had master's degree and average working time in oncology unit was $9.5 \mathrm{~h}$, and average age was 47.8. The interviews were conducted face to face and took at least 30-45 min. Whenever a problem was observed during the interviews, the researchers would contact the participant by phone and talk to him/her for 10-15 $\mathrm{min}$. The place in which the interview was conducted depended on the participants' preference. To start each interview, informed consent was received from participants to enter the procedure. Interviews were recorded with the permission of participants. Interviews were printed and given to participants, and they confirmed that the researcher had written the exact sentences they provided during the interview.

In this study, written consent was received from participants, and final results were given to them. In addition to continuous presence and involvement in 
data, primarily extracted codes and final results were investigated by a specialist in the context of patients with cancer to increase the validity and accuracy of the study.

\section{Data analysis}

All the collected data from the interviews were analyzed through a qualitative content analysis. Qualitative content analysis is an inductive method of analysis which is used to identify the codes and the categorizing and naming similar codes. After transcribing the interviews, they were coded. The coding process was included two main steps: Finding meaningful statements and naming them [18]. At first, 297 initial codes were extracted. Similar codes were categorized into themes and subthemes. Five themes and 14 subthemes were emerged. To ensure the reliability of coding, the first author manually categorized the data at first, and then, they were reviewed by the second author.

\section{Results}

\section{Review of literature: Theoretical phase}

Characteristics and definition of the concept: Oxford Dictionary defines "futile" or "futility" as a vain attempt for maintenance and survival. This term is derived from "fundere" which is a Latin term. Greiner in concept definition points to physiological and qualitative aspects that, in the first one, care is considered as a lack of achievement of physical objectives by the intervention. To explain this aspect, he states that if resuscitation cannot bring normal conditions back, it is a futile practice and indicates futility and defines qualitative futility as a condition, in which desirable conditions to achieve the objectives are challenged; however, the treatment may be effective, it is not valuable [12]. Cameron in defining futile care states that there is no clear definition and it is different according to the conditions of the patient and cultural and religious beliefs of the families, patients, and the treatment team [19]. According to Palda, futile care may not have a unified definition and it is different according to the conditions and personal values of nurses and is dependent on perspectives toward life, ethical beliefs, and judgment about treatment, and accordingly, the concept may be different in different societies [9]. Elpern states that futile care is referred to the measures that despite continuity do not lead to objectives and life improvement and nurses experience emotional suffering in the long-term period [20]. According to Davila, futile care is the absence or lack of effect to achieve certain objectives and if the objective of interest or desirable results is not met, it is called futile care [21]. Hariharan, in his definition, states that futile care includes a set of measures that are performed by the treatment team seriously and continuously for patients with lifethreatening conditions, but successful results are not expected [22]. Riechelman considers futile care as a set of caregiving measures accompanied by inability or ineffectiveness to achieve the objectives that include survival of the patient and then improvement in health conditions [23]. Franklin states that this concept is used when a patient who has experienced heart failure has arrived at the hospital and despite the reason for this problem, the possibility for recovery with resuscitation is $<3-5 \%$ [24]. According to Schneiderman, futile care is a complex concept that is related to the achievement of the objectives and means an ineffective activity and objectives of interest are not achievable through these cares and success and meeting the objectives empirically and tangibly is not possible through them [25]. Bray defines futile care as cases through which desirable conditions to achieve the objectives are questioned and along with the measures taken, the possibility of success is very low and almost impossible. Although the treatment may impact the organ, it is not valuable [26]. Halpren considers futile care as a set of continuous cares that may not lead to survival and no significant change occurs in this regard [27]. Dzeng states that this type of care including acceptable use of therapeutic resources may be performed with the expectation of improvement and save the patient against threatening conditions, but certain cases of futile care may be tragic for the health-care team members and do not lead to results and instead, lead to emotional suffering and facilitate job burnout, especially for nurses [28]. In this regard, Polakala states that futile care is a set of measures that if performed carefully both qualitatively and quantitatively, still the survival chance is $<5 \%$ [29]. According to the hybrid concept approach in last parts of the theoretical phase, concept characteristics and dimensions are characterized that are repeated during concept definition and without them, it is not possible to say that the concept has occurred. These characteristics can provide a clear image of the concept [15]. In Tables 1 and 2, important characteristics of futile care according to the previous studies are presented.

Final definition for the theoretical phase: According to reviews and characteristics considered for futile care based on the previous studies, the following practical definition can be proposed: Futile care in oncology unit means to present clinical scientific services including caregiving, diagnostic, rehabilitation, and continuous services for patients with life-threatening conditions that despite the provision of the mentioned measures, the survival chance from physiological and qualitative aspects will be below $5 \%$ and these measures are defined with low chance to meet the objectives with insignificant effect on survival of the patient. 
Table 1: Studies conducted on futile care concept

\begin{tabular}{|c|c|c|c|c|}
\hline Authors & Field & Characteristics & Occurrence & Consequences \\
\hline Griener, 1995 & $\begin{array}{l}\text { Treatment team's } \\
\text { independence in performing } \\
\text { or avoiding futile care }\end{array}$ & $\begin{array}{l}\text { Power and permission to select } \\
\text { a physician or nurse to provide } \\
\text { or avoid care }\end{array}$ & $\begin{array}{l}\text { Physiological futility: Failure of intervention to } \\
\text { achieve physical objectives. } \\
\text { Qualitative futility: Desirable conditions to } \\
\text { achieve objectives are questioned, although } \\
\text { treatment may be effective. }\end{array}$ & $\begin{array}{l}\text { Physiological aspect: Cardiopulmonary } \\
\text { resuscitation with vegetable life. } \\
\text { Qualitative aspect: Supporting mechanical } \\
\text { ventilation for a patient who is alive for several } \\
\text { days. }\end{array}$ \\
\hline Palda, 2005 & $\begin{array}{l}\text { The reason for performing } \\
\text { futile care from the } \\
\text { perspectives of nurses and } \\
\text { physicians working at ICU }\end{array}$ & $\begin{array}{l}\text { What are the perspectives of } \\
\text { nurses and physicians regarding } \\
\text { futile care for patients who are } \\
\text { under threatening conditions? }\end{array}$ & $\begin{array}{l}\text { Futile care is mostly dependent on } \\
\text { perspectives toward life and ethical beliefs } \\
\text { about successful and unsuccessful treatment } \\
\text { and it can be defined differently in different } \\
\text { societies }\end{array}$ & $\begin{array}{l}\text { Lack of a unified definition for futile care } \\
\text { Dependency attribution to: } \\
\text { - Condition of patient } \\
\text { - Individual values of the treatment team }\end{array}$ \\
\hline Elpern, 2005 & $\begin{array}{l}\text { Ethical distress of nurses in } \\
\text { ICU regarding futile care }\end{array}$ & $\begin{array}{l}\text { Anxiety, emotional suffering } \\
\text { against threatening conditions }\end{array}$ & $\begin{array}{l}\text { Futile care includes a set of measures } \\
\text { that despite continuity does not lead to the } \\
\text { objectives and survival and almost makes } \\
\text { nurses experience emotional distress for a } \\
\text { long time period }\end{array}$ & $\begin{array}{l}\text { Continuous care Up to date and scientific } \\
\text { interventions } \\
\text { Creating emotional suffering and distress for } \\
\text { nurses }\end{array}$ \\
\hline Heland, 2005 & $\begin{array}{l}\text { Experience and } \\
\text { understanding of nurses } \\
\text { regarding futile care }\end{array}$ & & $\begin{array}{l}\text { Futile care includes a set of sophisticated } \\
\text { measures with modern equipment and } \\
\text { multidimensional nursing care }\end{array}$ & $\begin{array}{l}\text { No significant effect on clinical improvement } \\
\text { Providing }\end{array}$ \\
\hline Devila, 2006 & $\begin{array}{l}\text { Cost and effectiveness } \\
\text { challenge from the } \\
\text { perspective of health } \\
\text { decision-makers about futile } \\
\text { care }\end{array}$ & $\begin{array}{l}\text { Providing qualitative and } \\
\text { quantitative futile services in } \\
\text { terms of cost and effectiveness } \\
\text { and its consequences }\end{array}$ & $\begin{array}{l}\text { Inability to achieve your objectives } \\
\text { Ambiguity regarding specific interventions that } \\
\text { are meaningless and ineffective } \\
\text { Uncertainty in identifying ineffective } \\
\text { interventions and a sense of failure in } \\
\text { providing futile care } \\
\text { If the aim is not met or the desired results are } \\
\text { achieved, it is futile care }\end{array}$ & $\begin{array}{l}\text { Lack of impact to fulfill specific needs } \\
\text { Failure to meet the objective }\end{array}$ \\
\hline Hariharan, 2007 & $\begin{array}{l}\text { Knowledge, attitude, and } \\
\text { performance of the health- } \\
\text { care team in providing futile } \\
\text { care }\end{array}$ & $\begin{array}{l}\text { The effect of awareness and } \\
\text { attitude of the health-care team } \\
\text { toward futile care }\end{array}$ & $\begin{array}{l}\text { Futile care includes a set of measures that is } \\
\text { performed by the health-care team seriously } \\
\text { and continuously for patients with threatening } \\
\text { conditions }\end{array}$ & $\begin{array}{l}\text { Serious and continuous care } \\
\text { Lack of improvement in conditions and } \\
\text { success }\end{array}$ \\
\hline Schneiderman, 2008 & $\begin{array}{l}\text { Improving futile drug } \\
\text { interventions }\end{array}$ & $\begin{array}{l}\text { Combined drug interventions } \\
\text { for patients with threatening } \\
\text { conditions }\end{array}$ & $\begin{array}{l}\text { Futile care is a complex concept that is related } \\
\text { to meeting the objectives }\end{array}$ & $\begin{array}{l}\text { Useless practice } \\
\text { Lack of achieving the goals empirically and } \\
\text { tangibly }\end{array}$ \\
\hline Frankline, 2011 & $\begin{array}{l}\text { Futile care in patients with } \\
\text { cancer }\end{array}$ & $\begin{array}{l}\text { The impact and importance } \\
\text { of futile care for patients with } \\
\text { cancer }\end{array}$ & $\begin{array}{l}\text { Resuscitating a patient with heart failure where } \\
\text { there is no hope for survival }\end{array}$ & $\begin{array}{l}\text { The recovery possibility with resuscitation is } \\
<3-5 \%\end{array}$ \\
\hline Bray, 2013 & $\begin{array}{l}\text { Cost and prevalence of futile } \\
\text { care in patients with cancer }\end{array}$ & $\begin{array}{l}\text { Development of futile care } \\
\text { application in patients with } \\
\text { threatening conditions }\end{array}$ & $\begin{array}{l}\text { Cases through which desirable conditions are } \\
\text { questioned } \\
\text { Providing care with low success possibility due } \\
\text { to low life quality }\end{array}$ & $\begin{array}{l}\text { Lack of chance to meet the objectives } \\
\text { Effective treatment but the ineffective impact }\end{array}$ \\
\hline Dzeng, 2015 & $\begin{array}{l}\text { The effect of culture and } \\
\text { policies on preventing } \\
\text { resuscitation as futile care }\end{array}$ & $\begin{array}{l}\text { Accepting futile care according } \\
\text { to the culture and policies of } \\
\text { health and treatment system }\end{array}$ & $\begin{array}{l}\text { Acceptable use of resources may be } \\
\text { accompanied by expecting improvement and } \\
\text { survival of a patient with threatening conditions }\end{array}$ & $\begin{array}{l}\text { Failure to meet the objectives in some } \\
\text { instances of futile care for the health-care } \\
\text { team } \\
\text { Emotional suffering and increased job burnout } \\
\text { of nurses }\end{array}$ \\
\hline Yekefallah, 2015 & $\begin{array}{l}\text { Understanding the } \\
\text { experience of nurses } \\
\text { regarding futile care }\end{array}$ & $\begin{array}{l}\text { Dependence of definition and } \\
\text { understanding of futile care from } \\
\text { the perspective of nurses }\end{array}$ & $\begin{array}{l}\text { Ineffective care that wastes capital and suffers } \\
\text { patients and nurses }\end{array}$ & $\begin{array}{l}\text { Waste of energy } \\
\text { Unprofessional measures } \\
\text { Suffering patients and nurses }\end{array}$ \\
\hline Polakala, 2017 & $\begin{array}{l}\text { Knowledge and attitude } \\
\text { of nurses and physicians } \\
\text { relative to futile care }\end{array}$ & $\begin{array}{l}\text { Can care be fundamentally } \\
\text { futile? }\end{array}$ & $\begin{array}{l}\text { A set of measures that if performed accurately } \\
\text { and continuously, may not increase the } \\
\text { survival of patients }\end{array}$ & $\begin{array}{l}\text { Providing careful and accurate qualitative and } \\
\text { quantitative interventions } \\
\text { Low survival chance } \\
\text { High-quality care is the patient's right }\end{array}$ \\
\hline
\end{tabular}

\section{Fieldwork phase}

After finishing the data analysis, the researchers compared all the themes emerging from the interview data with the themes created through literature review, and the similarities and differences between the emerged themes and those obtained through literature review were jotted down. The resulted themes pointed out in Table 3.

\section{conditions}

Theme 1: Caregiving under life-threatening

Participants have taken these issues into consideration more specifically that despite high therapeutic costs and attempts for patient survival, their life quality is low and their life is dependent on caregiving equipment, and most of the interventions are painful for the patient and the lowest costs are related to direct nursing care that has the highest tangible effect on patients' satisfaction but is ignored. This theme includes two subthemes of "difficult life" and "low-quality life."

\section{Difficult life}

Imagine we have a patient with advanced lung cancer with liver and bone metastases, and due to chemotherapy with Adriamycin, his EF is $20 \%$ meaning that with these conditions, heart failure is added to his problems and why this patient should pass cardiopulmonary resuscitation (CPR) for 3 consecutive days, and the only option may be connected to machine, and other options are ineffective, and his survival suffers him and his family and only causes pain and expenses.

\section{Low-quality life}

I believe that in our religion it is important to save people and even in Quran, it is mentioned that we should help all people but the conditions we have, a patient with CLL and lung involvement who is experiencing multiple organ dysfunction syndromes and has disseminated intravascular coagulation, CPR would not help and even after CPR, the consciousness level of the patient is very low. Also, it is not clear how 
Table 2: Essential characteristics of futile care according to the previous studies

\begin{tabular}{lll}
\hline Number & Source & Characteristics \\
\hline 1 & Cameron, 1986; Dunwoody 2010 [32] & Lack of clear definition \\
2 & Griener, 1995; Tomlinson, 2001 [33]; Polakala, 2017 & Two-dimensional futile care including physiological and qualitative care \\
3 & Palda, 2005; Yekefallah, 2015; Dzeng, 2015 & Dependence of futile care definition on beliefs, ethics, and values of the health-care team \\
4 & Elpern, 2005; Hariharan, 2007 & Continuous and comprehensive care \\
5 & Dzeng, 2015; Sibbald, 2007; Yekefallah, 2015 & Care accompanied by ethical distress and mental suffering for the health-care team \\
6 & Davil, 2006; Melteze, 2004 [34]; Bray, 2013 & Care accompanied by a failure to meet the objectives \\
7 & Polakala, 2017; Dzeng, 2015 & Low chance for survival \\
8 & Schneiderman, 2008; Yekefallah, 2015 & Diagnostic, therapeutic, caregiving, and rehabilitating measures with low success \\
9 & Persaud, 2006 & Providing caregiving interventions for patients with threatening conditions and low life quality \\
10 & Elpern, 2005; Heland, 2005 & Updated interventions with very low effectiveness \\
11 & Hariharan, 2007; Schneiderman, 2008 & Providing services seriously and comprehensively \\
\hline
\end{tabular}

Table 3: Futile care attributes based on fieldwork

\begin{tabular}{|c|c|c|}
\hline $\mathrm{Nu}$ & Them & Subtheme \\
\hline Number & Themes & Subthemes \\
\hline \multirow[t]{2}{*}{1} & \multirow{2}{*}{$\begin{array}{l}\text { Care for life-threatening } \\
\text { conditions }\end{array}$} & Difficult life \\
\hline & & Low-quality life \\
\hline \multirow[t]{2}{*}{2} & \multirow[t]{2}{*}{$\begin{array}{l}\text { Failure to regain hemostasis } \\
\text { balance and life }\end{array}$} & $\begin{array}{l}\text { No improvement in the patient's physiological } \\
\text { conditions }\end{array}$ \\
\hline & & No chance for survival \\
\hline \multirow[t]{3}{*}{3} & \multirow{3}{*}{$\begin{array}{l}\text { Ineffectiveness and } \\
\text { unprofessional duties }\end{array}$} & Purposeless \\
\hline & & Incompatible \\
\hline & & Unprofessional duties \\
\hline \multirow[t]{5}{*}{4} & \multirow{5}{*}{$\begin{array}{l}\text { Professional problems } \\
\text { following futile care }\end{array}$} & Ethical distress \\
\hline & & Patient's resentment \\
\hline & & Nurse's resentment \\
\hline & & Job burnout \\
\hline & & Wasted costs \\
\hline \multirow[t]{2}{*}{5} & \multirow[t]{2}{*}{ Beliefs of nurses } & Performing all orders and cares \\
\hline & & Evidence-based care \\
\hline
\end{tabular}

much pain the patient experiences. But what about respect? Even if the patient recovers after resuscitation, he cannot control urination. Is this a high-quality life? As far as I know, it is better not to disturb the patient is dying.

\section{Theme 2: Failure to return homeostatic balance and survival}

This theme indicated that participants, despite continuous and comprehensive care, believed that according to modern medical science, these patients due to physiological conditions and simultaneous involvement of multiple organ dysfunction syndromes would not survive, but care is provided. Interventions are painful, accompanied by more suffering for the patient. This theme includes two subthemes of "failure to improve the physiological conditions of the patient" and "no chance for survival."

Failure to improve the physiological conditions of the patient

We had a patient with advanced bone marrow cancer with metastasis to both lungs, and during chemotherapy in the oncology unit, the patient experienced heart arrest and transferred to ICU with GCS 3. The physician after visit said that the patient would not survive, but nobody told to avoid resuscitation, and the physician, despite being hopeless about his survival, asked for several examinations, and then, costly drugs were administered for the patient. Moreover, the patient's financial status was not good at all. I did not understand how his family prepared the drugs. Finally, after 2 weeks and passing CPR, the patient died.

\section{No chance for survival}

We have a patient who receives many drugs such as adrenaline, norepinephrine, and dopamine, but still, his blood pressure is between 6 and 7 , and without one of these drugs, he will not be alive for several hours. Furthermore, his kidney does not function for 2 weeks. With these conditions, this patient undergoes dialysis 2 times a week. Moreover, every day, he receives many new drugs and TPNs. This patient is alive by these drugs and is actually dead.

\section{Theme 3: Ineffectiveness}

After an interview with participants, the most frequent issue addressed by them was that these services are purposeless and cannot improve health levels and recreate a high-quality life. Most participants consider purposeful care as improvement in physical conditions where the patient benefits from services. From the perspective of participants, effective care is beneficial to care with minimum side effects that improve the physical conditions of the patient. This theme includes two subthemes of "purposeless care" and "incompatible care."

\section{Purposeless care}

We try to do our best to do something for the patient and observe tangible and good results after that. However, sometimes we have patients that modern equipment cannot do anything for them, and the only miracle can make some changes, and intense and high-quality care cannot be helpful.

\section{Incompatible care}

We had a patient who was suffering from colon cancer with pancreatic metastases and did not indicate suitable general conditions. Surgery was performed about 4 times, and he had a colostomy, and 6 months ago, he was diagnosed by pancreatic metastases. After 3 months, he could not tolerate any food, all digestive enzymes were disturbed and he could not tolerate gavage. After the initiation of TPN, within $<2$ weeks, he experienced sepsis phase. He was receiving many drugs daily, but it was not helpful. Although all orders were followed carefully, no improvement was observed and to be clear, and we were implementing a series of 
futile and purposeless measures to let him pass those days.

\section{Unprofessional duties}

Seven participants pointed to this issue that if you do something different from direct and indirect care, it is futile and unprofessional. Since nurses do not have clear duty description, they should perform a series of tasks that are not practically useful for patients and can be considered as futile care, because the nurse has performed them, but they are not helpful. Ambiguity in duty description of nurses prevents implementation of tasks and from management perspective, decreases effectiveness, and increases futile care.

Very often, I think about tasks that are given to us in hospital that are not helpful and effective, and one of them is that in the very crowded ICU and its very sick patients, you should look for opiate, and strange drugs that are ordered after each visit and another problem emerges that how it should be started with these terrible economic conditions and for patients who are very sick and there is no hope for recovery and improvement.

\section{futile care}

Theme 4: Professional problems following

One of the themes of ethical issues was dealing with patients with cancer and under lifethreatening conditions that created many emotional issues for nurses in providing care and permanent care for very sick patients was the same. Furthermore, most interventions were very painful and suffering for nurses and patients.

\section{Ethical distress}

I do my best to accurately perform all orders and cares that my sick patient needs. Sometimes, I dedicate more time for that but sometimes, mainly when painful procedures exist, and costly drugs are ordered, I ask for domestic medications, and the physician confirms my request but after that, there is a doubt if the original one could be effective but again, I see the patient and tell myself I worked in favor of the patient and his family, but this is in my head all the time.

\section{Nurse's resentment}

Very often, after a long period of chemotherapy, the patient's veins do not function properly, and if there is no catheter and port, taking blood and arterial blood gas would be a very big problem. This is very hard to perform orders and see the patient suffers if he is conscious. If you have to work with patients with these conditions, your emotions will be negatively influenced.

\section{Patient's resentment}

Very often, when we are performing invasive care for a patient who is spending his last days, and the procedure is very painful, you can feel the suffering in the patient's eyes. Sometimes, after experiencing this condition, I could not see the patient for several hours. She was a young girl with ovarian cancer and peritoneal metastases, and she was unconscious. I had to take an arterial blood sample but indeed, for this patient, it was impossible, but the anesthesia unit needed that for device mode setting. I cannot forget when she was begging with her eyes not to do that.

\section{Job burnout}

Our job is challenging and has many challenges. We even have many problems against ordinary patients, let alone those who have very difficult conditions and are going to die. Suppose a patient with this condition and no money, and you have to take care of him because you feel responsibility. How much can you work in this condition?

\section{Wasted costs}

One of the crucial subthemes taken into consideration by participants was related to the costs that occurred after the threatening conditions for patients and families and caused no benefit for the patient.

You see, the patient who is transferring between the unit and ICU like a dead person and every new drug is used and every minute a new visit is conducted. Frequent computed tomography scans and magnetic resonance imaging and also frequent blood sampling asking to take your patient to different laboratories and spending a lot of money. These procedures may not help. I do not say we should ignore these patients, but this patient should be in a hospice center beside the family. If you ask this from patients, they say the same.

\section{Theme 5: Beliefs of nurses}

One theme, especially in our culture as Muslims, addressed by four participants was that medical science is not everything, and we are not supposed to determine patients' fate. We as professionals and at the same time, Muslim people are responsible for supporting patients until the last moment but at the same time, several participants approved this issue but did not consider all the procedures beneficial for patients. In section 2, two parts of two different interviews are presented.

\section{Performing all orders and cares}

The label "end stage" may look simple for us, but the patient may regain health. I am working at 
oncology for almost 15 years and I have seen patients with threatening conditions regained their health. We are not God and we have to follow orders and perform them accurately.

\section{Evidence-based care}

I was a nurse, know that I have studied 4 years to take care of patients and there should not be any bias against different patients and they should receive care equally. But sometimes, you can help the patient through careful implementation of orders. It is not reasonable to implement whatever the procedure says and this is not the evidence-based treatment that is frequently pointed out in in-service themes. Care should benefit the patient and numerous interventions do not imply excellent and high-quality procedures.

\section{Final analytical phase}

The objective of this phase was to compare, combine, and weigh the results of interviews and review of texts to achieve the final analysis [30]. The general analysis was performed combining and integrating previous phases. First of all, the codes extracted in theoretical and work in the field phases were compared and then, a comprehensive definition was presented. Futile care includes a set of therapeutic, diagnostic, clinical care, and even rehabilitation based on modern science and these interventions are performed seriously and continuously by all health-care team members. However, these interventions will not guarantee the survival of patients both physically and qualitatively and there is a low chance of obtaining good results.

Furthermore, implicitly and explicitly, consequences proposed thatincluded multidimensionality of futile care, low clinical effectiveness, limited survival chance, and dependence of services based on values and beliefs of the health-care team. In the data resulted from fieldwork, features such as providing care for patients with life-threatening conditions, ineffective interventions, multidimensional care, and dependence of definition on beliefs and attitudes of nurses are addressed.

In the present study, seven concepts about futile care resulted that all of them are similar to the concepts produced from previous studies. Taking care of patients with life-threatening conditions and low life quality were concepts common to prior studies. In a study by Persaud, futile care is proposed when the effect of treatment is too weak and ineffective and cannot influence the patient's life (17). Meltzer stated that futile care means clinical conditions in which the explanations provided by the physician and the health-care team point out that this care does not help the treatment and will not bring relief for the patient, does not recover life quality, and may not lead to satisfaction [31]. Another concept included care under life-threatening conditions that according to reviews and also Devila [21] and Yekefallah [10], futile care includes the provision of services when the patient is under critical and life-threatening conditions and suffers from failure in several organs and his life is dependent on interventions.

Furthermore, failure for physiological recovery was another concept that was common with reviews. Neiderman et al. believed that care is futile when no perspective exists about results and the physiological conditions cannot be compensated [1]. Futile care occurs when the effect of interventions is not desirable but the main question in defining this concept is that do the interventions benefit the patient? Improvement has clinical influence and this perspective toward care effectiveness exists when we obtain the desired results, but the problem is that what is the benefit of this intervention? Here, the concept of futile care forms whether the intervention was effective. The lack of effectiveness in the definition of futile care is addressed in many studies such as Elpern who defines futile care as continuous care but despite accurate implementation, it does not improve patient's conditions and life quality [20]. Another concept resulted from fieldwork is professional problems following futile care that lead to moral distress, patient's resentment, nurse's resentment, and job burnout, and in studies by Dzeng, futile care is accompanied by ethical distresses for patients to do or not to do these cares [28]. Furthermore, according to Yekefalah, futile care for patients with terrible conditions is accompanied by mental distress for nurses and physical suffering for patients that is consistent with the results of fieldwork [10]. In a study by Sibbald, this issue is taken into consideration that continuous care for patients under life-threatening conditions leads to job burnout for nurses and reduces their interest in working at these unites [2].

One of the concepts includes values and beliefs of the health-care team about the definition of futile care that stated the results of fieldwork including implementation of all orders and the necessity to perform all evidence-based interventions, and in this regard, Palda states that beliefs of nurses and physicians regarding human and life influence the definition of futile care [9]. Besides all findings resulted from reviews, a major concept of our analysis following interview with participants was the provision of unprofessional duties that are pointed out in all texts except Yekefallah that several participants stated that comprehensive services by the nurse save time for direct care. In all text reviews in this study, futile care services are defined professionally and scientifically. For example, in a study by Heland, futile care is defined as scientific and professional care continuously and seriously [5]. Since the findings of the present study are consistent with Yekefallah [10] that is conducted on the nursing society of Iran, it seems that according to one of the concepts, the values and beliefs of nurses are effective. The reason for considering 
futile care as unprofessional care in the Iranian nursing context is related to the working conditions of nurses in this country. In Iran, unfortunately, nurses do not have well-defined duties and in most centers and hospitals, there is no balance between nurses and patients and this does not provide the opportunity to present complex care for very sick patients. Consequences resulted from futile care showed high interaction between what was resulted from reviews and fieldwork. High costs (for system and families), job burnout, and damaging other patients were among consequences of futile care. The reasons to perform futile care that indicates interaction between theoretical phase and fieldwork phase included ethical issues and mental and physical pressures for a nurse, fear of legal constraints, physician's attitude, lack of proper relationship between the medical team and patient and families, religious issues, emotions, and lack of clear guidelines.

\section{Conclusion}

The findings of this study presented the definition of futile care in nursing from patients hospitalized in the oncology unit and provided a suitable context for evaluation and application of this concept. Finally, it can be said that futile care is a concept that is under the influence of issues such as ethics, religion, beliefs, views toward nursing, error commitment, uncertain prognosis of diseases, lack of certified clinical guide, clinical services unrelated to nursing practice, and cares by which the patient cannot be recovered physiologically and qualitatively. The most important consequences include high costs, job burnout, a patient's resentment, and a nurse's resentment. However, it seems that to clarify the details of this concept in the cultural and social context governing the health system of the country, more studies and practice are needed. Concept analysis is an endless process and is felt as far as knowledge and experiences are available [20]. Therefore, the findings of this study are the starting point for more studies in this context. Identification of futile care features leads to the promotion and application of this concept in the nursing context and especially for nurses who take care of patients under threatening conditions.

\section{Acknowledgment}

The authors appreciate the friendly cooperation of participants and the oncology unit of Shohadaye Tajrish Hospital and palliative care center of Tehran University of Medical Science.

\section{Authors' Contributions}

All authors contributed to this project and article equally. All authors read and approved the final manuscript.

\section{References}

1. Niederman MS, Berger JT. The delivery of futile care is harmfu to other patients. Crit Care Med. 2010;38(10):S518-22. https:// doi.org/10.1097/ccm.0b013e3181f1cba5

PMid:21164391

2. Sibbald R, Downar J, Hawryluck L. Perceptions of "futile care" among caregivers in intensive care units. CMAJ. 2007;177(10):1201-8. https://doi.org/10.1503/cmaj.070144 PMid:17978274

3. Biley F. Nursing redefined: Emergent insights from studying the art and science of nursing in Germany and Switzerland. Theoria. 2005;14(2):23-6.

4. Siegel RL, Miller KD, Fedewa SA, Ahnen DJ, Meester RG, Barzi A, et al. Colorectal cancer statistics, 2017. CA Cancer J Clin. 2017;67(3):177-93. https://doi.org/10.3322/caac.21395 PMid:28248415

5. Heland M. Fruitful or futile: Intensive care nurses' experiences and perceptions of medical futility. Aust Crit Care. 2006;19(1):25-31. https://doi.org/10.1016/s1036-7314(06)80020-2

PMid:16544676

6. Aghabarari M, Dehghan Nayeri N. Futile care: Challenges of applying futility concept in caring domain. J Hayat. 2015;21(1):1-5

7. Mobley MJ, Rady MY, Verheijde JL, Patel B, Larson JS. The relationship between moral distress and perception of futile care in the critical care unit. Intensive Crit Care Nurs. 2007;23(5):25663. https://doi.org/10.1016/j.iccn.2007.03.011 PMid:17681468

8. Bahramnezhad F, Asgari $P$, Sanaie N, Fathi A Futilecare: A conceptanalysis with Walker and Avant's approach. Iran J Cancer Nurs. 2019;1(1):48-54. https://doi.org/10.29252/ ijca.1.1.48

9. Palda VA, Bowman KW, McLean RF, Chapman MG. "Futile" care: Do we provide it? Why? A semistructured, Canada-wide survey of intensive care unit doctors and nurses. J Crit Care. 2005;20(3):207-13. https://doi.org/10.1016/j.jcrc.2005.05.006 PMid: 16253788

10. Yekefalah L, Ashktorab T. Experiences of critical care units nurses about futile care a qualitative study. Prev Care Nurs Midwifery J. 2015;4(2):23-34

11. Kopelman LM. Conceptual and moral disputes about futile and useful treatments. J Med Philos. 1995;20(2):109-21. https://doi. org/10.1093/jmp/20.2.109 PMid:7636418

12. Griener GG. The physician's authority to withhold futile treatment. J Med Philos. 1995;20(2):207-24. PMid:7636422

13. Scanlon A, Murphy M. Medical futility in the care of noncompetent terminally ill patient: Nursing perspectives and responsibilities. Aust Crit Care. 2014;27(2):99-102. https://doi. org/10.1016/j.aucc.2012.10.003

PMid:23218919 
14. Broom A, Kirby E, Good P, Lwin Z. Nursing futility, managing medicine: Nurses' perspectives on the transition from lifeprolonging to palliative care. Health. 2016;20(6):653-70. https:// doi.org/10.1177/1363459315595845

\section{PMid:26208696}

15. Schwartz-Barcott D. An expansion and elaboration of the hybrid model of concept development. Concept Development in Nursing Foundations, Techniques, and Applications. Philadelphia, PA: Saunders; 2000. p. 129-59.

16. Salsali M, Pour A, Movahedi A. Principles and Techniques of Concept Development. Tehran: Boshra Publications; 2007.

17. Persaud R, editor "Futile" Care in the Intensive Care Unit. Amsterdam, Netherlands: Mayo Clinic Proceedings, Elsevier; 2006. https://doi.org/10.4065/81.11.1506-a

18. Hsieh HF, Shannon SE. Three approaches to qualitative content analysis. 2005;15(9):1277-88.

PMid: 16204405

19. Cameron M. The moral and ethical component of nurse-burnout Nurs Manag. 1986;17(4):42D-E.

PMid:3634263

20. Elpern EH, Covert B, Kleinpell R. Moral distress of staff nurses in a medical intensive care unit. Am J Crit Care. 2005;14(6):523-30. https://doi.org/10.4037/ajcc2005.14.6.523 PMid:16249589

21. Davila F. The infinite costs of futile care-the ultimate physician executive challenge. Physician Exec. 2006;32(1):60-3 PMid:16509403

22. Hariharan S, Jonnalagadda R, Gora J. Knowledge, attitudes and practices of healthcare personnel towards care-ethics: A perspective from the Caribbean. Int $\mathrm{J}$ Law Healthc Ethics. 2007;5(1):2. https://doi.org/10.5580/1928

23. Riechelmann RP, Zimmermann C, Chin SN, Wang L, O'Carroll A, Zarinehbaf $\mathrm{S}$, et al. Potential drug interactions in cancer patients receiving supportive care exclusively. J Pain Symptom Manage. 2008;35(5):535-43. https://doi.org/10.1016/j. jpainsymman.2007.06.009

PMid:18243638

24. Franklin GA, Cannon RW, Smith JW, Harbrecht BG, Miller FB, Richardson JD. Impact of withdrawal of care and futile care on trauma mortality. Surgery. 2011;150(4):854-60. https://doi. org/10.1016/j.surg.2011.07.065

PMid:22000200

25. Schneiderman LJ, Jecker NS. Wrong Medicine: Doctors Patients, and Futile Treatment. Baltimore, Maryland: JHU Press; 2011.

26. Bray F, Ren JS, Masuyer E, Ferlay J. Global estimates of cancer prevalence for 27 sites in the adult population in 2008. Int $J$ Cancer. 2013;132(5):1133-45. https://doi.org/10.1002/ijc.27711 PMid:22752881

27. Halpern SD. Toward evidence-based end-of-life care. N Engl J Med. 2015;373(21):2001.

PMid:26465826

28. Dzeng E, Colaianni A, Roland M, Chander G, Smith TJ, Kelly MP, et al. Influence of institutional culture and policies on do-not-resuscitate decision making at the end of life. JAMA Int Med. 2015;175(5):812-9. https://doi.org/10.1001/ jamainternmed.2015.0295 PMid:25845020

29. Polakala S, Hariharan S, Chen D. Knowledge and attitudes of medical and nursing practitioners regarding non-beneficial futile care in the intensive care units of Trinidad and Tobago. Clin Ethic. 2017;12(2):95-101. https://doi.org/10.1177/1477750917691886

30. Boswell C, Cannon S. Introduction to Nursing Research Burlington: Jones and Bartlett Learning; 2018.

31. Meltzer LS, Huckabay LM. Critical care nurses' perceptions of futile care and its effect on burnout. Am J Crit Care. 2004;13(3):202-8. https://doi.org/10.4037/ajcc2004.13.3.202 PMid:15149054

32. Tomlinson T, MichalskiAJ, Pentz RD, Kuuppelomäki M. Futile care in oncology: When to stop trying. LancetOncol2001;2(12):759-64 https://doi.org/10.1016/s1470-2045(01)00592-7 PMid:11902519

33. Dunwoody DR. Nurses' Level of Moral Distress and Perception of Futile Care in the Critical Care Environment. United States: D’Youville College; 2010.

34. Meltzer LS, Huckabay LM. Critical care nurses' perceptions of futile care and its effect on burnout. Am J Crit Care 2004;13(3):202-8. https://doi.org/10.4037/ajcc2004.13.3.202 PMid:15149054 